\title{
Identification and Assessment of Genetic Similarity of Soil Bacterial Isolates of Pseudomonas spp. Using Molecular Techniques
}

\author{
ANNA LISEK*, LIDIA SAS PASZT AND PAWEŁ TRZCIŃSKI
}

Research Institute of Horticulture, Skierniewice, Poland

Submitted 12 March 2014, revised 23 May 2014, accepted 25 May 2014

Abstract

\begin{abstract}
Bacteria of the genus Pseudomonas are often components of bioproducts designed to enhance the condition of the soil and plants. The use of Pseudomonas bacteria in bioproducts must be preceded by the acquisition, characterization and selection of beneficial strains living in the soil. A prerequisite for the selection of bacterial strains for use in bioproducts is to be able to identify the isolates rapidly and accurately. To identify and differentiate 15 bacterial isolates obtained from the soil surrounding the roots of sour cherry trees and to assess their genetic similarity, the rep-PCR technique and restriction analysis of the 16S rRNA gene and the 16S-ITS-23S rRNA operon were used. In addition, a sequence analysis of the $16 \mathrm{~S}$ rRNA gene was performed. The analyses made it possible to divide the isolates into four clusters and to confirm their affiliation with the Pseudomonas species. RFLP analysis of the 16S-ITS-23S rRNA operon enabled greater differentiation of the isolates than RFLP of the $16 \mathrm{~S}$ rRNA gene. The greatest differentiation of isolates within the clusters was obtained after using the rep-PCR technique. However, none of the techniques was able to discriminate all the isolates, which indicates very high genetic similarity of the Pseudomonas isolates found in the same sample of soil from around the roots of sour cherry trees. The tests performed will find application for distinguishing and identifying Pseudomonas strains collected from the soil in order to select the most valuable bacterial strains that produce beneficial effects on plants.
\end{abstract}

Key words: $16 \mathrm{~S}$ rRNA, 16S-ITS-23S rRNA operon, RFLP, rep-PCR

\section{Introduction}

Progress in organic agriculture makes it necessary to develop new bioproducts that are suitable for the cultivation of fruit plants and contribute at the same time to improving the quality of soils under perennial crops, such as fruit orchards. To develop such bioproducts, it is necessary to acquire and isolate strains of beneficial bacteria from the soil environment. Among the bacteria that produce favourable effects on plants there are many strains belonging to the genus Pseudomonas. It has been established that strains of Pseudomonas spp. are important microorganisms in the rhizosphere, and that is why considerable research work is being conducted to exploit the potential of these bacteria for improving the quality of soils and the growth, yielding and protection of plants (Choudhary et al., 2009).

Pseudomonas spp. are aerobic, Gram-negative bacteria, ubiquitous in agricultural soils, and well-adapted to growing in the rhizosphere (Weller, 2007). Bacteria of the genus Pseudomonas are often found in cultivated soils, including the rhizosphere of plants, or in other substrates, such as oil-contaminated sand (McSpadden Gardener et al., 2000; Mavrodi et al., 2001; Susilowati et al., 2010; Mulet et al., 2011). Pseudomonas bacteria have many valuable attributes that make them highly suitable for use in bioproducts. These bacteria quickly colonize the rhizosphere and plant roots, produce bioactive metabolites, such as antibiotics and siderophores (compounds stimulating plant growth), inhibit the growth of pathogenic microorganisms, increase the resistance of plants to diseases, and, moreover, they can be multiplied in the laboratory (Weller, 2007; Choudhary et al., 2009). Pseudomonas bacteria are characterized by a broad spectrum of beneficial effects on plants; their action is often synergistic with other rhizosphere bacteria and mycorrhizal fungi beneficial to plants. Pseudomonas fluorescens and Pseudomonas putida strains have the ability to promote plant growth and drive developmental plasticity in the roots of Arabidopsis thaliana by inhibiting primary root elongation and promoting the formation of lateral roots and root hairs (Zamioudis et al., 2013). Pseudomonas bacteria have been found to stimulate the growth and increase fruit

* Corresponding author: A. Lisek, Konstytucji 3 Maja 1/3, 96-100 Skierniewice, Poland; e-mail: anna.lisek@inhort.pl 
yields of sweet cherry trees (Esitken et al., 2006). PGPB (Plant Growth Promoting Bacteria), including those of the genus Pseudomonas, are known to stimulate fruit set and vegetative growth of 'Kütahya' sour cherry trees, which indicates the possibility of employing them in sustainable and ecological agricultural systems (Karakurt et al., 2011). However, there is no information on the bacteria that colonize the rhizosphere soil of sour cherry trees grown organically, from which new useful strains could potentially be isolated.

The development of new bioproducts makes it necessary to identify and select the beneficial strains of Pseudomonas bacteria from the rhizosphere soil. The necessary condition in the characterization and selection of soil bacterial strains is the ability to quickly and accurately distinguish and identify the isolates. The basic method is to differentiate isolates on the basis of the morphological features of bacterial colonies, i.e. shape, colour, size, structure and type of edges (Aquilanti et al., 2004a). The selection of beneficial strains of rhizosphere bacteria also relies on the techniques of biochemical identification (Rana et al., 2011). However, unambiguous identification of bacteria at the level of species and strains by classical methods is often difficult because of the high variability in phenotypic traits (Jayarao et al., 1992; Aquilanti et al., 2004a). For this reason, techniques based on DNA analysis are used in the identification and discrimination of bacterial isolates or strains.

To identify and differentiate genera and species of bacteria, and to assess their genetic similarity, sequence analysis of the 16S rRNA gene (Mulet et al., 2011; Susilowati et al., 2010; Yang et al., 2008; Charbonneau et al., 2012) or restriction analysis of the 16S rRNA gene with the ARDRA technique (amplified ribosomal DNA restriction analysis) (Aquilanti et al., 2004a; 2004b; Yang et al., 2008; Susilowati et al., 2010) is used. To differentiate bacteria at the species level, restriction analysis of the 16S-ITS-23S bacterial ribosomal operon is also used. Research in this area suggests that this technique is a universal and reliable tool for genotyping bacteria (Abd-El-Haleem et al., 2002; Zeng et al., 2012).

The genomes of bacteria contain a large number of dispersed repetitive DNA sequences. These sequences are located at distant intergenic positions throughout the genome (Choudhary et al., 2009). To differentiate bacterial species and strains, three families of repetitive sequences are used, namely Repetitive Extragenic Palindromic (REP) sequence, Enterobacterial Repetitive Intergenic Consensus (ERIC) sequence, and the BOX element. The rep-PCR technique employs primers that bind to repetitive sequences, which enables generation of DNA profiles for bacterial strains and species. By using the rep-PCR technique, it is possible to discriminate bacteria even down to the subspecies, strain, or isolate level (Louws et al., 1994; Ishii and Sadowsky, 2009).
All of the above-mentioned techniques have been used for the differentiation of bacteria of the genus Pseudomonas. However, RFLP analysis of the 16S-ITS$23 \mathrm{~S}$ rRNA operon has been used for Pseudomonas bacteria only once, when evaluating the suitability of this technique for the differentiation of bacterial genomes from different taxonomic groups (Zeng et al., 2012).

The aim of the study was to identify and determine the genetic similarity of isolates of Pseudomonas bacteria inhabiting the soil around the roots of sour cherry trees grown in the organic system. Furthermore, the aim of the study was to compare the usefulness of the PCR-RFLP technique for the 16S-ITS-23S rRNA operon with the ARDRA and rep-PCR techniques for differentiating isolates of soil bacteria.

\section{Experimental}

\section{Materials and Methods}

Preparation of soil bacterial isolates. The experimental material comprised isolates of bacteria obtained from the soil around the roots of sour cherry trees growing in the Ecological Orchard of the Institute of Horticulture in Nowy Dwór (51 $\left.51^{\prime} 35^{\prime \prime} \mathrm{N}, 20^{\circ} 16^{\prime} 46^{\prime \prime} \mathrm{E}\right)$. The bacteria were isolated from the soil by plating successive dilutions on Petri dishes containing S1 medium, which is selective for bacteria of the genus Pseudomonas (Gould et al., 1985). Next, the dishes with bacterial colonies were incubated for seven days at a temperature of $28^{\circ} \mathrm{C}$. All the isolates were subjected to Gram staining, and the production of the pigment fluorescein on S1 medium was determined.

DNA extraction. Extraction of DNA from bacterial colonies was carried out by means of a commercial GeneMatrix Bacterial \& Yeast Genomic DNA Purification Kit for isolating DNA from bacteria and yeast (EURx). DNA concentration in the samples was measured with a spectrophotometer at a wavelength of $260 \mathrm{~nm}$. For further analyses, the samples were diluted to a final concentration of $10 \mathrm{ng} / \mu \mathrm{l}$.

RFLP analysis. For RFLP analysis, the $16 \mathrm{~S}$ rRNA gene and the 16S-ITS-23S rRNA bacterial ribosomal operon were amplified. The $16 \mathrm{~S}$ rRNA gene was amplified using 1492r/27f primers (Lane, 1991). The 16S-ITS$23 \mathrm{~S}$ rRNA operon was amplified using 63f/23SrPrimer4 (Abd-El-Haleem et al., 2002). Reaction mixtures $(20 \mu \mathrm{l})$ consisted of $1 \times$ buffer for PCR, $0.2 \mathrm{mM}$ of each nucleotide, $0.2 \mu \mathrm{M}$ of each primer, $0.5 \mathrm{U}$ of DreamTaq ${ }^{\mathrm{TM}}$ polymerase (ThermoScientific ${ }^{\circledR}$ ) and 20 ng DNA. Amplification of the 16S rRNA gene was carried out in 35 cycles $\left(94^{\circ} \mathrm{C} \times 1 \mathrm{~min} ., 55^{\circ} \mathrm{C} \times 1 \mathrm{~min} ., 72^{\circ} \mathrm{C} \times 2 \mathrm{~min}\right.$.) and amplification of the 16S-ITS-23S rRNA operon was carried out in 25 cycles $\left(94^{\circ} \mathrm{C} \times 15 \mathrm{~s}, 64^{\circ} \mathrm{C} \times 30 \mathrm{~s}, 68^{\circ} \mathrm{C} \times 5 \mathrm{~min}\right.$.). 
Restriction analysis of the 16S rRNA gene and the 16S-ITS-23S rRNA bacterial ribosomal operon was performed using FastDigest HaeIII, TaqI and RsaI enzymes $\left(\right.$ ThermoScientific $\left.{ }^{\circledR}\right)$. Restriction digestion of the amplified fragments was carried out in $30 \mu \mathrm{l}$ of a reaction mixture containing $17 \mu$ deionized water, $2 \mu \mathrm{l}$ of $10 \mathrm{x}$ reaction buffer, $1 \mu \mathrm{l}$ of one restriction enzyme, and $10 \mu \mathrm{l}$ of template DNA. Restriction fragments were separated on $2.5 \%$ agarose gel, stained with ethidium bromide and visualized under UV light.

rep-PCR analysis. The rep-PCRs were carried out using complementary primers for repetitive sequences in the bacterial genome: ERIC, REP, and BOX (Louws et al., 1994). The reaction mixture $(20 \mu \mathrm{l})$ consisted of $1 \times$ buffer for PCR, $0.2 \mathrm{mM} \mathrm{MgCl}_{2}, 0.25 \mathrm{mM}$ of each nucleotide, $0.75 \mu \mathrm{M}$ of each primer, $1.5 \mathrm{U}$ of DreamTaq ${ }^{\mathrm{TM}}$ polymerase (ThermoScientific ${ }^{\odot}$ ) and $25 \mathrm{ng}$ DNA. The following thermal profiles of the reactions were used: REP-PCR - 42 cycles $\left(94^{\circ} \mathrm{C} \times 1 \mathrm{~min} ., 52^{\circ} \mathrm{C} \times 1 \mathrm{~min}\right.$., $65^{\circ} \mathrm{C} \times 8 \mathrm{~min}$.); ERIC-PCR -42 cycles $\left(94^{\circ} \mathrm{C} \times 1 \mathrm{~min}\right.$., $52^{\circ} \mathrm{C} \times 1.5 \mathrm{~min}$., $65^{\circ} \mathrm{C} \times 8 \mathrm{~min}$.); BOX-PCR -37 cycles $\left(94^{\circ} \mathrm{C} \times 1 \mathrm{~min} ., 40^{\circ} \mathrm{C} \times 2 \mathrm{~min} ., 72^{\circ} \mathrm{C} \times 2 \mathrm{~min}\right.$.).

The products of the reactions were separated on a $2 \%$ agarose gel, stained with ethidium bromide and visualized under UV light. Each reaction was repeated three times on the same DNA matrix. Only informative, clear and reproducible products of the reactions were analyzed.

Sequence analysis of the $16 \mathrm{~S}$ rRNA gene. Amplification of the $16 \mathrm{~S}$ rRNA gene in PCR was performed under the same conditions as for RFLP analysis. Determination of similarity of the obtained sequences with the 16S rRNA gene sequences of bacteria was carried out using the BLAST tool via the National Center for Biotechnology Information (NCBI) website.

Data analysis. On the basis of the data obtained with the RFLP techniques for the 16S rRNA gene (ARDRA) and the 16S-ITS-23S rRNA operon, and with the rep-PCR technique, a genetic similarity analysis of the isolates was made using XLSTAT software (Addinsoft 2006) based on the Jaccard coefficient. The results were used to construct dendrograms depicting the genetic similarity of the isolates. Multiple
16S rRNA gene sequence alignments were performed with MEGA 5.2 using CLUSTAL W. A phylogenetic tree was constructed using the neighbour-joining method with a bootstrap analysis based on 1000 resampling of the dataset.

\section{Results}

From the soil collected near the roots of sour cherry trees we obtained 15 isolates of bacteria growing on S1 medium, which is selective for bacteria of the genus Pseudomonas: Ps20A, Ps20J, Ps20N, Ps20N1, Ps20N2, Ps20P, Ps20S, Ps20T, Ps20Z, Ps20Z1, Ps20Z2, Ps20X1, Ps20X2, Ps20Om1, Ps20Om2. On the basis of Gram staining, we found that all the isolates were Gram negative. Among the 15 strains, 13 showed the ability to produce the pigment fluorescein, while the remaining two strains, Ps20X1 and Ps20X2, did not produce this pigment.

RFLP analysis. The length of the PCR products was approx. $1490 \mathrm{bp}$ for the 16S rRNA gene and approx. 4000 bp for the 16S-ITS-23S rRNA operon. By using the HaeIII enzyme, we obtained monomorphic profiles for all the isolates tested. Digestion of the products of amplification of the 16S rRNA gene with restriction enzymes TaqI and RsaI resulted in 14 DNA fragments ranging in length from $75 \mathrm{bp}$ to $800 \mathrm{bp}$, nine of which constituted fragments differentiating the isolates. The analysis enabled us to distinguish two isolates, Ps20P and Ps20J, while for the remaining isolates we obtained the same DNA pattern (Table I).

Digestion of the products of amplification of the 16S-ITS-23S rRNA operon with restriction enzymes resulted in $37 \mathrm{DNA}$ fragments ranging in length from $120 \mathrm{bp}$ to $1100 \mathrm{bp}$, out of which 30 fragments enabled us to differentiate the isolates. As a result of RFLP analysis of the 16S-ITS-23S rRNA operon, we were able to distinguish isolates Ps20J, Ps20P, Ps20T and a group of isolates Ps20X1 and Ps20X2 (Table II). The DNA profiles of the remaining 10 isolates were monomorphic.

PCR-RFLP analysis enabled us to divide the isolates into groups according to the profiles obtained.

Table I

DNA fragments obtained by restriction analysis of the 16S rRNA gene for soil bacterial isolates of Pseudomonas spp.

\begin{tabular}{|l|c|l|l|}
\hline Enzyme & Pattern & Observed fragments (bp) & \multicolumn{1}{c|}{ Isolates } \\
\hline \multirow{3}{*}{ TaqI } & $\mathrm{A}$ & $760,340,200,100$ & $\begin{array}{l}\text { Ps20A, Ps20N, Ps20N1, Ps20N2, Ps20S, Ps20T, Ps20X1, Ps20X2, Ps20Z, Ps20Z1, Ps20Z2, } \\
\text { Ps20Om1, Ps20Om2 }\end{array}$ \\
\cline { 2 - 4 } & $\mathrm{B}$ & $460,360,310,200,100$ & Ps20J \\
\cline { 2 - 4 } & $\mathrm{C}$ & $760,350,200,75$ & Ps20P \\
\hline \multirow{2}{*}{ RsaI } & $\mathrm{D}$ & $800,350,160,120$ & $\begin{array}{l}\text { Ps20A, Ps20J, Ps20N, Ps20N1, Ps20N2, Ps20S, Ps20T, Ps20X1, Ps20X2, Ps20Z, Ps20Z1, } \\
\text { Ps20Z2, Ps20Om1, Ps20Om2 }\end{array}$ \\
\cline { 2 - 5 } & $\mathrm{E}$ & $610,350,230,160,120$ & Ps20P \\
\hline
\end{tabular}


Table II

DNA fragments obtained by restriction analysis of the 16S-ITS-23S rRNA operon for soil bacterial isolates of Pseudomonas spp.

\begin{tabular}{|l|c|l|l|}
\hline Enzyme & Pattern & \multicolumn{1}{|c|}{ Observed fragments $(\mathrm{bp})$} & \multicolumn{1}{|c|}{ Isolates } \\
\hline \multirow{4}{*}{ TaqI } & $\mathrm{F}$ & $820,600,550,480,390,350,290,210,180,120$ & $\begin{array}{l}\text { Ps20A, Ps20N, Ps20N1, Ps20N2, Ps20S, Ps20T, Ps20Z, Ps20Z1, } \\
\text { Ps20Z2, Ps20Om1, Ps20Om2 }\end{array}$ \\
\cline { 2 - 4 } & $\mathrm{G}$ & $590,520,500,450,430,380,340,210,180,120$ & Ps20J \\
\cline { 2 - 4 } & $\mathrm{H}$ & $820,480,470,390,350,290,250,210,180$ & Ps20P \\
\cline { 2 - 4 } & $\mathrm{I}$ & $820,560,490,390,370,350,290,210,180,120$ & Ps20X1, Ps20X2 \\
\hline \multirow{4}{*}{ RsaI } & $\mathrm{J}$ & $930,800,680,580,360,210,150$ & $\begin{array}{l}\text { Ps20A, Ps20N, Ps20N1, Ps20N2, Ps20S, Ps20Z, Ps20Z1, Ps20Z2, } \\
\text { Ps20Om1, Ps20Om2 }\end{array}$ \\
\cline { 2 - 4 } & $\mathrm{K}$ & $1000,820,680,360,280,210,150$ & Ps20J \\
\cline { 2 - 5 } & $\mathrm{L}$ & $840,680,600,360,260,210,150$ & Ps20P \\
\cline { 2 - 4 } & $\mathrm{M}$ & $980,800,680,360,210,150$ & Ps20X1, Ps20X2 \\
\cline { 2 - 4 } & $\mathrm{N}$ & $1100,800,680,580,360,210,150$ & Ps20T \\
\hline
\end{tabular}

The analysis of the 16S rRNA gene resulted in 3 DNA patterns, while the analysis of the 16S-ITS-23S rRNA operon produced 5 DNA patterns, which allowed the isolates to be divided into groups of bacteria. The dendrogram created on the basis of RFLP analysis of all the DNA fragments identified 4 clusters (Fig. 1). Isolates Ps20P and Ps20J were two separate clusters; isolates Ps20X1 and Ps20X2 were one cluster. Isolate Ps20T was most similar to the remaining 10 isolates and together they constituted a separate cluster.

rep-PCR analysis. As a result of the reactions, we obtained a total of 79 polymorphic DNA fragments, from $200 \mathrm{bp}$ to $3500 \mathrm{bp}$ in length. The largest number of the polymorphic fragments (34) was obtained by using the REP primers. In the reactions with the ERIC primers, we obtained 22 polymorphic DNA fragments, while the BOX-PCR reactions produced 23 differentiating DNA fragments.

In the reactions with the BOX primers, we distinguished isolates Ps20P, Ps20J and the group of isolates
Ps20X1 and Ps20X2. The remaining 11 isolates had the same DNA profiles. The products of ERIC-PCRs allowed us to distinguish the same isolates as in the BOX-PCRs, and, in addition, there was one polymorphic fragment that enabled us to distinguish isolate Ps20A. For the remaining 10 isolates, monomorphic DNA patterns were produced. In the REP-PCRs, we distinguished isolates Ps20P, Ps20J and the group of isolates Ps20X1 and Ps20X2. Moreover, the presence of one polymorphic fragment enabled us to distinguish the group of isolates Ps20Om1 and Ps20Om2. The remaining 9 isolates formed a cluster with the same DNA profiles.

The dendrogram constructed on the basis of the data obtained by the rep-PCR technique made it possible to divide the isolates into four clusters (Fig. 2). One of them was formed by isolates Ps20X1 and Ps20X2. Two separate clusters were made up of isolates Ps20P and Ps20J. The remaining isolates formed one cluster. After carrying out the rep-PCRs, it was impossible to

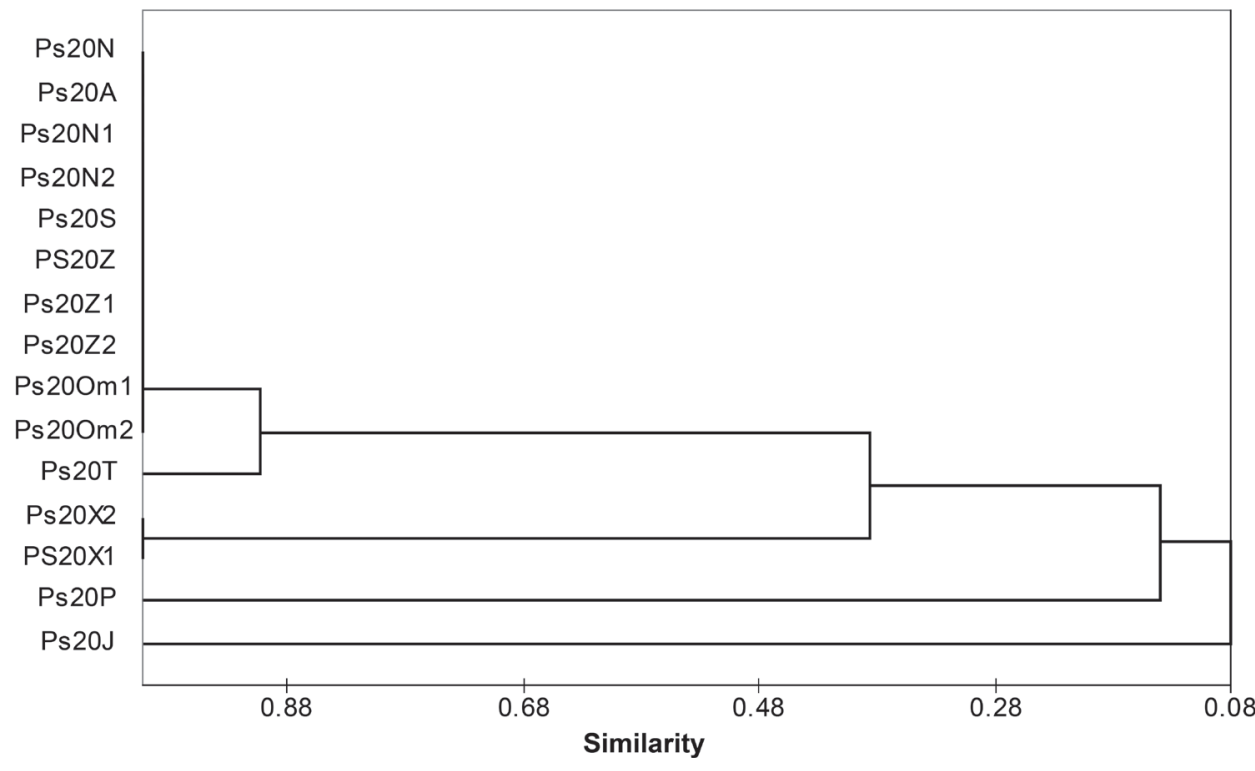

Fig. 1. Dendrogram showing the genetic similarity of soil bacterial isolates, obtained on the basis of RFLP analysis of the 16S rRNA gene and the 16S-ITS-23S operon. The dendrogram was constructed using the UPGMA (unweighted pairgroup mean) method based on the Jaccard coefficient. 
Fig. 2. Dendrogram showing the genetic similarity of soil bacterial isolates, obtained on the basis of rep-PCR analysis. The dendrogram was constructed using the UPGMA (unweighted pair-group mean) method based on the Jaccard coefficient.

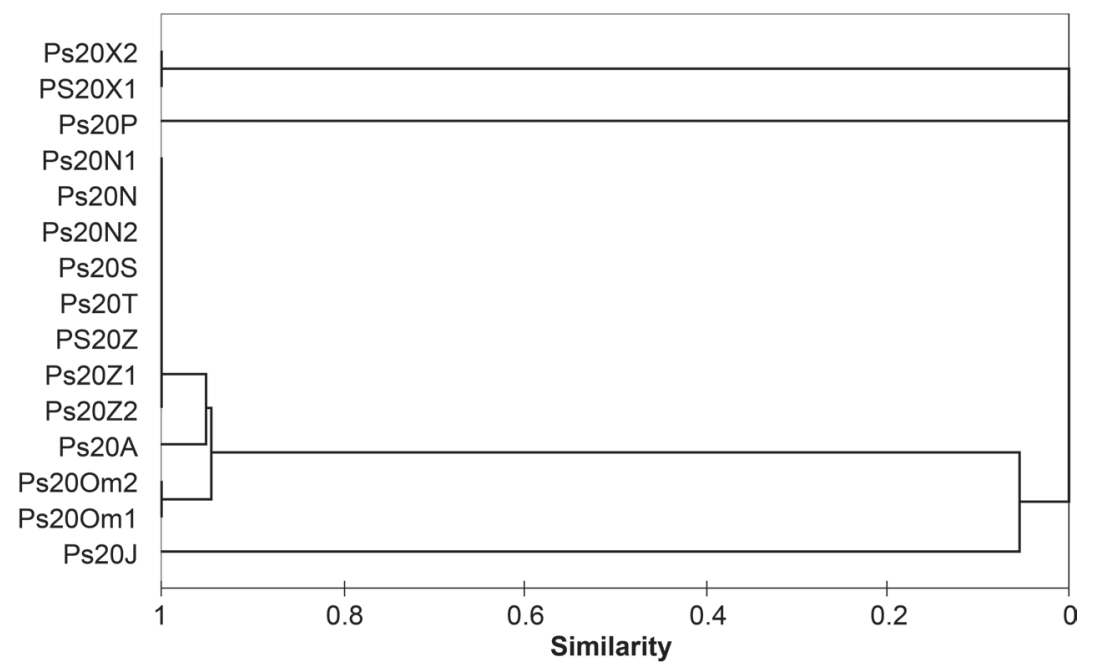

differentiate isolates: Ps20X1 and Ps20X2, Ps20Om1 and Ps20Om2, and group of 8 isolates, Ps20N, Ps20N1, Ps20N2, Ps20S, Ps20T, Ps20Z, Ps20Z1 and Ps20Z2.

Sequence analysis of the 16S rRNA gene. Comparison of the sequence of the 16S rRNA gene of the tested isolates with the sequences in the NCBI database revealed high similarity of the isolates to Pseudomonas spp. (98-99\%). The sequences of the 16S rRNA gene of isolates Ps20A, Ps20N, Ps20N1, Ps20N2, Ps20S, Ps20T, Ps20Z, Ps20Z1, Ps20Z2, Ps20Om1, and Ps20Om2 showed $99 \%$ similarity to P. fluorescens. The sequence of $16 \mathrm{~S}$ rRNA of isolate Ps20J showed the strongest similarity (99\%) to Pseudomonas reinekei or to P.fluorescens. The sequence of isolate Ps20P was to the extent of $99 \%$ the most similar to P. putida, and the sequences of isolates Ps20X1 and Ps20X2 to Pseudomonas jessenii (98\%). The dendrogram constructed on the basis of the sequence analysis of the 16S rRNA gene divided the isolates into 3 clusters (Fig. 3). One cluster con- tained isolates Ps20X1 and Ps20X2, the second Ps20P, while the third cluster contained isolate Ps20J and the remaining 11 isolates.

\section{Discussion}

From the soil surrounding the roots of sour cherry trees we obtained 15 bacterial isolates, whose colonies grew on S1 medium, which is selective for the genus Pseudomonas. By comparing the sequence of the $16 \mathrm{~S}$ rRNA gene with the sequences stored in the NCBI database, we were able to confirm that all the isolates belonged to the genus Pseudomonas. The sequence of the 16S rRNA gene of isolate Ps20J showed the greatest similarity to the species $P$. reinekei and $P$. fluorescens. Strain MT1, identified as a novel species $P$. reinekei, had been isolated from a polluted aerobic sediment of the River Elbe (Cámara et al., 2007). The sequence of the 16S rRNA gene of isolate Ps20J indicates strong
Fig. 3. Dendrogram showing the genetic similarity of soil bacterial isolates, obtained on the basis of sequence analysis of the $16 \mathrm{~S}$ rRNA gene. The neighbour-joining tree was constructed using the Kimura 2-parameter model; nodal supports were evaluated by 1000 bootstrap replicates.

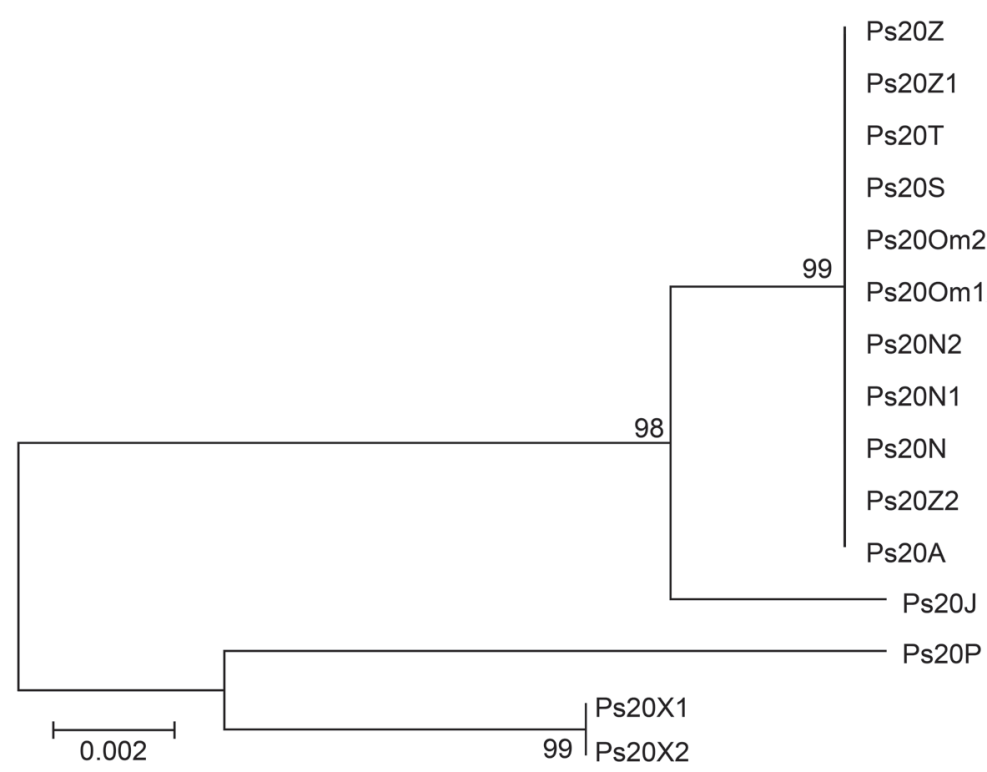


similarity to this species, but to confirm that it belongs to $P$. reinekei requires additional molecular and biochemical tests. Based on the current results, we classified isolate Ps20J into the group of fluorescent Pseudomonas spp. Isolates Ps20X1 and Ps20X2 showed the strongest similarity to the species $P$. jessenii. However, the fact that these isolates did not produce the pigment fluorescein suggests that they may belong to another species of the genus Pseudomonas, and therefore, on the basis of the results obtained thus far, we classified them as Pseudomonas sp.

The techniques of DNA analysis employed in the study enabled us to determine the similarity of the isolates to four species of the genus Pseudomonas. However, none of these molecular techniques could differentiate all the isolates. The greatest genetic similarity was in a group of 11 isolates, Ps20A, Ps20N, Ps20N1, Ps20N2, Ps20S, Ps20T, Ps20Z, Ps20Z1, Ps20Z2, Ps20Om1 and Ps20Om2. Using the rep-PCR technique, we were able to distinguish isolate Ps20A and group of isolates Ps20Om1 and Ps20Om2, while RFLP analysis of the 16S-ITS-23S rRNA operon enabled us to distinguish one bacterial isolate from this group, Ps20T.

In the present study, the least informative was the RFLP analysis of the 16S rRNA gene (ARDRA), which allowed us to identify three groups of isolates. The ARDRA technique is used to differentiate genera or species of bacteria. It has helped to obtain unique species-specific RFLP patterns of Azotobacter bacteria (Aquilanti et al., 2004a, 2004b). The technique has enabled identification of genera and species of riceassociated bacteria (Yang etal., 2008). ARDRA has also helped to isolate groups of antifungi-producing Pseudomonas rhizobacteria, which corresponded with the clusters obtained by $16 \mathrm{~S}$ rRNA sequence analysis (Susilowati et al., 2010). Sometimes, however, a high sequence identity of the 16S rRNA gene among bacterial species causes difficulties in distinguishing them (Zeng et al., 2012). For example, the sequences of the $16 \mathrm{~S}$ rRNA gene of different strains of acetic acid bacteria are very similar to one another, which causes problems in the identification of the species (Trček and Teuber, 2002). Problems in the identification of species and subspecies of bacteria on the basis of 16S rRNA RFLP analysis make it necessary to analyze other regions of ribosomal genes, characterized by greater variation than 16S rRNA, such as the ITS region or 23S rRNA.

In the present study, RFLP analysis of the 16S-ITS$23 \mathrm{~S}$ rRNA operon enabled us to separate out 5 groups of isolates and was more effective in differentiating the isolates than RFLP of the 16S rRNA gene, which divided the bacteria into 3 groups. RFLP analysis of the 16S-ITS-23S rRNA operon allowed us to distinguish one isolate - Ps20T, which could not be distinguished with the other techniques of DNA analysis.
The PCR-RFLP technique enables analysis of the ribosomal bacterial operon containing the $16 \mathrm{~S}$ rRNA and $23 \mathrm{~S}$ rRNA subunits and the region between them - the internal transcribed spacer (ITS) (Abd-ElHaleem, 2002; Yavuz et al., 2004; Zeng et al., 2012; Charbonneau et al., 2012). The presence of at least one copy consisting of $16 \mathrm{~S}$ rRNA, ITS and 23S rRNA has been found in each of the 885 published genomes of bacteria belonging to different genera, which indicates that the set of the 16S-ITS-23S ribosomal genes is an essential component in the bacterial genome and is the basis for the application of the long PCR-RFLP method (Zeng et al., 2012). The region 16S-ITS-23S rRNA varies considerably between bacterial species and genera, and the variation in size of that region is associated with the variable size of ITS and the 23S rRNA gene, while the size of the 16S rRNA gene is not subject to any major changes (Zeng et al., 2012). For these reasons, analysis of the 16S-ITS-23S rRNA region makes it possible to differentiate the more closely related bacteria, and may be more useful for differentiating bacteria than the ARDRA technique based on the analysis of the 16S rRNA gene. PCR-RFLP analysis of the 16S-ITS-23S operon has enabled division of thermophilic bacterial strains from manure compost into four clusters corresponding to four bacterial genera, and has also helped to distinguish two subgroups among Geobacillus thermodenitrificans isolates (Charbonneau et al., 2012). PCR-RFLP analysis of the 16S-ITS-23S operon has also been effective in distinguishing Ralstonia eutropha even at the strain level (Abd-El-Haleem et al., 2002).

To differentiate bacteria, analysis is also made of a part of the ribosomal operon, such as the ITS region or the 16S-ITS rRNA gene. For example, restriction analysis of the ITS1 region has enabled differentiation of Pseudomonas species (Franzetti and Scarpellini, 2007). RFLP analysis of the ITS region has also enabled identification of acetic acid bacteria (Trček and Teuber, 2002). PCR-RFLP analysis of the 16S-ITS rRNA gene has made it possible to differentiate Lactobacilli at the species level (Yavuz et al., 2004). In addition, RFLP analysis of the 16S rRNA gene and ITS1 region has helped to distinguish biotypes of P. fluorescens, which differ in the production of levan (Scarpellini et al., 2004).

In this study, RFLP analysis of both the $16 \mathrm{~S}$ rRNA gene and the entire 16S-ITS-23S rRNA operon was possible with the use of TaqI and RsaI enzymes. This confirms the computer-simulated RFLP analysis of the 16S-ITS-23S sequence of rRNA genes conducted for 885 bacterial genomes, which showed that these enzymes were the most useful in the restriction analysis of the bacterial operon (Zeng et al., 2012). The use of the HaeIII enzyme has enabled RFLP analysis of acetic acid bacteria based on the ITS region (Trček and Tauber, 
2002), but it proved to be useless in our study with bacteria of the genus Pseudomonas.

The rep-PCR technique is used to differentiate bacteria at the level of species, subspecies and strains (Gevers et al., 2001; Ishii and Sadowsky, 2009). In the results presented here, rep-PCR analysis enabled us to identify 4 clusters of isolates. The use of BOX, ERIC and REP primers made it possible to distinguish isolates Ps20P, Ps20J and a cluster of isolates Ps20X1 and Ps20X2. In addition, within the cluster of 11 isolates with the strongest similarity to P. fluorescens, the ERICPCRs enabled us to distinguish isolate Ps20A, while the REP-PCRs allowed us to distinguish isolates Ps20Om 1 and Ps20Om2 from the other isolates.

Differences in the determination of the genetic similarity of bacteria of the genus Pseudomonas with the rep-PCR technique as dependent on the primers used have also been observed in other studies. The use of ERIC primers has enabled better differentiation of Pseudomonas avellanae strains than the use of BOX or REP primers (Scortichini et al., 2000). In an assessment of the genetic diversity of Pseudomonas strains originating from the rhizosphere and containing the phlD gene, separate groups of bacteria among isolates with the same BOX pattern have been distinguished on the basis of ERIC patterns (McSpadden Gardener et al., 2000). A greater genotypic diversity of Pseudomonas syringae strains has been obtained in BOX-PCRs than in ERICPCRs (Kaluzna et al., 2010). When distinguishing isolates of Pseudomonas spp., more discriminating DNA profiles have been obtained with REP than with ERIC or BOX primers (Lisek et al., 2011). Differences in the usefulness of primers for rep-PCRs are also observed when analyzing the genetic diversity of bacterial genera other than Pseudomonas spp. The REP-PCR method has proved to be more informative and more effective than BOX-PCR in the differentiation of species of the genus Geobacillus (Meintanis et al., 2008). The BOX-PCR method has also been the most useful for the identification of thermophilic strains of bacteria of the genera Geobacillus, Anoxybacillus and Bacillus (Adiguzel et al., 2009). The results of our study and data from the world literature indicate that the use of all the REP, ERIC and BOX primers makes it possible to obtain greater biodiversity and to distinguish a larger number of bacterial species and strains with the rep-PCR technique.

As a result of the rep-PCR analysis, it was not possible to distinguish three groups consisting of 8,2 and 2 isolates. The fact that the same bacterial DNA profiles were obtained indicates very strong similarity of the isolates isolated from the same soil sample. The result is similar to that of rep-PCR analysis of strains of fluorescent Pseudomonas spp., where the dominant genotype was observed for isolates isolated from the same soil sample (McSpadden Gardener et al., 2000).
In the identification and differentiation of bacteria, the rep-PCR technique is used in conjunction with the ARDRA technique, which allows a more precise discrimination of isolates to the level of species, subspecies, or even strains. When ARDRA patterns obtained for phlD-containing Pseudomonas strains showed very strong similarity, it was only by using the rep-PCR technique that it was possible to identify 17 genotypes among 3 ARDRA groups (McSpadden Gardener et al., 2000). The ARDRA technique has also helped to isolate among rice-associated bacteria a group of 139 bacterial strains belonging to the genus Bacillus, while the BOXPCR technique enabled discrimination of those strains to the level of species or subspecies (Yang et al., 2008). Our own studies have shown that the best discrimination of isolates is obtained with the rep-PCR technique. Similar results have been obtained after comparing the rep-PCR and ARDRA techniques in the differentiation of strains of fluorescent Pseudomonas spp. (McSpadden Gardener et al., 2000).

The phylogenetic analyses performed on the basis of the obtained sequences of $16 \mathrm{~S}$ rRNA, using RFLP of the 16S-ITS-23S rRNA operon and rep-PCR, enabled us to identify bacterial isolates from the soil surrounding the roots of sour cherry trees to the level of species of the genus Pseudomonas. The least effective in differentiating the isolates was RFLP analysis of the 16S rRNA gene. The rep-PCR technique enabled us to distinguish the largest number of isolates. None of the techniques used made it possible to differentiate all the isolates, which indicates very high genetic similarity of the isolates of Pseudomonas bacteria originating from the same soil sample collected near the roots of sour cherry trees. Results of our own research and data of other authors confirm that the differentiation and identification of soil bacterial isolates require the use of several molecular techniques, which increases the effectiveness of identification (Franzetti and Scarpellini, 2007).

Our studies have enabled optimization and selection of appropriate methods to increase the effectiveness of identification of soil bacterial isolates of the genus Pseudomonas, and of the species and strains of that genus. The tests performed will be used to differentiate and identify isolates and strains of Pseudomonas colonizing the rhizosphere of fruit trees and other cultivated plant species. This will enable effective selection of the most valuable and economically important bacterial strains that produce beneficial effects on plants. The best strains and species of the beneficial soil microorganisms will become valuable components of microbiological preparations for organic and integrated production of crop plants. Moreover, the results obtained will be used for molecular characterization of microorganisms beneficial to plants, deposited in SymbioBank of the Institute of Horticulture in Skierniewice (Poland). 


\section{Acknowledgements}

The work has been supported by a grant 'Development of innovative products and technologies for organic fruit production, $\mathrm{co}_{-}$ financed from the EU Regional Development Fund through the Polish Innovation Economy Operational Programme.

\section{Literature}

Abd-El-Haleem D., A.C. Dayton and G.S. Sayler. 2002. Long PCRamplified rDNA for PCR-RFLP- and Rep-PCR-based approaches to recognize closely related microbial species. J. Microbiol. Meth. 49: 315-319.

Adiguzel A., H. Ozkan, O. Baris, K. Inan, M. Gulluce and F. Sahin. 2009. Identification and characterization of thermophilic bacteria isolated from hot springs in Turkey. J. Microbiol. Meth. 79: 321-328.

Aquilanti L., F. Favilli and F. Clementi. 2004a. Comparison of different strategies for isolation and preliminary idntification of Azotobacter from soil samples. Soil Biol. Biochem. 36: 1475-1483. Aquilanti L., I. Mannazzu, R. Papa, L. Cavalca and F. Clementi. 2004b. Amplified ribosomal DNA restriction analysis for the characterization of Azotobacteraceae: a contribution to the study of these free-living nitrogen-fixing bacteria. J. Microbiol. Meth. 57: 197-206. Cámara B., C. Strömpl, S. Verbarg, C. Spröer, D.H. Pieper and B.J. Tindall. 2007. Pseudomonas reinekei sp. Nov., Pseudomonas moorei sp. Nov. and Pseudomonas mohnii sp. Nov., novel species capable of degrading chlorosalicylates or isorimaric acid. Int. J. Syst. Evol. Microbiol. 57: 923-931.

Charbonneau D.M., F. Meddeb-Mouelhi, M. Boissinot, M. Sirois and M. Beauregard. 2012. Identification of thermophilic bacterial strains producing thermotolerant hydrolytic enzymes from manure compost. Indian J. Microbiol. 52: 41-47.

Choudhary K.D., A. Prakash, V. Wray and B.N. Johri. 2009. Insights of the fluorescent pseudomonads in plant growth regulation. Curr. Sci. India 97: 170-179.

Esitken A., L. Pirlak, M. Turan and F. Sahin. 2006. Effects of floral and foliar application of plant growth promoting rhizobacteria (PGPR) on yield, growth and nutrition of sweet cherry. Sci. Hortic. Amsterdam 110: 324-327.

Franzetti L. and M. Scarpellini. 2007. Characterisation of Pseudomonas spp. isolated from foods. Ann. Microbiol. 57: 39-47.

Gevers D., G. Huys and J. Swings. 2001. Applicability of rep-PCR fingerprinting for identification of Lactobacillus species. FEMS Microbiol. Lett. 205: 31-36.

Gould W.D., C. Hagedorn, T.R. Bardinelli and R.M. Zablotowicz. 1985. New selective media for enumeration and recovery of fluorescent pseudomonads from various habitats. Appl. Environ. Microbiol. 49: $28-32$.

Ishii S. and M.J. Sadowsky. 2009. Applications of the rep-PCR DNA fingerprinting technique to study microbial diversity, ecology and evolution. Environ. Microbiol. 11: 733-740.

Jayarao B.M., J.T. Dore and S.P. Oliver. 1992. Restriction fragment length polymorphism analysis of $16 \mathrm{~S}$ ribosomal DNA of Streptococcus and Enterococcus species of bovine origin. J. Clin. Microbiol. 30: 2235-2240.

Kaluzna M., P. Ferrante, P. Sobiczewski and M. Scortichini. 2010. Characterization and genetic diversity of Pseudomonas syringae from stone fruits and hazelnut using repetitive-PCR and MLST. J. Plant. Pathol. 92: 781-787.

Karakurt H., R. Kotan, F. Dadaşoğlu, R. Aslantaş and F. Şahin. 2011. Effects of plant growth promoting rhizobacteria on fruit set, pomological and chemical characteristics, color values, and vegetative growth of sour cherry (Prunus cerasus cv. Kütahya). Turk. J. Biol. 35 283-291. Doi:10.3906/biy-0908-35
Lane D.J. 1991. 16S/23S rRNA sequencing, pp. 115-175. In: Stackebrandt E. and M. Goodfellow (eds). Nucleic acid techniques in bacterial systermatics. John Wiley \& Sons Ltd, Chichester, United Kingdom.

Lisek A., L. Sas Paszt, M. Oskiera, P. Trzciński, A. Bogumił, A. Kulisiewicz and E. Malusá. 2011. Use of the rep-PCR technique for differentiating isolates of rhizobacteria. J. Fruit Ornam. Plant Res. 19: 5-12.

Louws F.J., D.W. Fulbright, C. Taylor Stephens and F.J. De Bruijn. 1994. Specific Genomic fingerprints of phytopathogenic Xanthomonas and Pseudomonas pathovars and strains generated with repetitive sequences and PCR. Appl. Environ. Microbiol. 7: 2268-2295.

Mavrodi O.V., B.B. McSpadden Gardener, D.V. Mavrodi, R.F. Bonsall, D.M. Weller and L.S. Thomashow. 2001. Genetic diversity of phlD from 2,4-diacetylphloroglucinol-producing fluorescent Pseudomonas spp. Phytopathology 91: 35-43.

McSpadden Gardener B.B., K.L. Schroeder, S.E. Kalloger, J.M. Raaijmakers, L.S. Thomashow and D.M. Weller. 2000. Genotypic and phenotypic diversity of phlD-containing Pseudomonas strains isolated from the rhizosphere of wheat. Appl. Environ. Microbiol. 66: 1939-1946.

Meintanis C., K.I. Chalkou, K.Ar. Kormas, D.S. Lymperopoulou, E.A. Katsifas, D.G. Hatzinikolaou and A.D. Karagouni. 2008. Application of $r p o \mathrm{~B}$ sequence similarity analysis, REP-PCR and BOX-PCR for the differentiation of species within the genus Geobacillus. Lett. Appl. Microbiol. 46: 395-401.

Mulet M., Z. David, B. Nogales, R. Bosch, J. Lalucat and E. GarcíaValdés. 2011. Pseudomonas diversity on crude-oil-contaminated intertidal sand samples obtained after the Prestige oil spill. Appl. Environ. Microbiol. 2011: 1076-1085.

Rana A., B. Saharan, M. Joshi, R. Prasanna, K. Kumar and L. Nain. 2011. Identification of multi-trait PGPR isolates and evaluating their potential as inoculants for wheat. Ann. Microbiol. 61: 893-900.

Scarpellini M., L. Franzetti and A. Galli. 2004. Development of PCR assay to identify Pseudomonas fluorescens and its biotype. FEMS Microbiol. Lett. 236: 257-260.

Scortichini M., U. Marchesi, M.P. Rossi, L. Angelucci and M.T. Dettori. 2000. Rapid identification of Pseudomonas avellanae field isolates, causing hazelnut decline in Central Italy, by repetitive PCR genomic fingerprinting. J. Phyopathol. 148: 153-159.

Susilowati A., A.T. Wayhudi, Y. Lestar, S. Wiyono and A. Suwanto. 2010. Genetic diversity of antifungi-producing rhizobacteria of Pseudomonas sp. isolated from rhizosphere of soybean plant. Microbiol. Indones. 4: 33-38.

Trček J. and M. Teuber. 2002. Genetic and restriction analysis of the 16S-23S rDNA internal transcribed spacer regions of the acetic acid bacteria. FEMS Microbiol. Lett. 208: 69-75.

Weller D.M. 2007. Pseudomonas biocontrol agents of soilborne pathogens: Looking back over 30 years. Phytopathology 97: 250-256. Yang J-H., H-X Liu, G-M Zhu, Y-L Pan, L-P Xu and J-H Guo. 2008. Diversity analysis of antagonists from rice-associated bacteria and their application in biocontrol of rice diseases. J. Appl. Microbiol. 104: 91-104.

Yavuz E., H. Gunes, C. Bulut, S. Harsa and A.F. Yenidunya. 2004. RFLP of 16S-ITS rDNA region to differentiate Lactobacilli at species level. World J. Microb. Biot. 20: 535-537.

Zamioudis C., P. Mastranesti, P. Dhonukshe, I. Blilou and C.M.J. Pieterse. 2013. Unraveling Root Developmental Programs Initiated by Beneficial Pseudomonas spp. Bacteria. Plant Physiol. 162: 304-318.

Zeng Y.H., M. Kobližžek, Y-X Li, Y.P. Liu, F.Y. Feng, J.D. Ji, J.C Jian and Z.H. Wu. 2012. Long PCR-RFLP of 16S-ITS-23S rRNA genes: a high-resolution molecular tool for bacterial genotyping. J. Appl. Microbiol. 114: 433-447. 